\title{
Genetic and correlation analysis of oleoresin chemical components in slash pine
}

\author{
S. Zhang*, J. Jiang* and Q. Luan \\ Research Institute of Subtropical Forestry, Chinese Academy of Forestry, \\ Hangzhou, China \\ *These authors contributed equally to this study. \\ Corresponding author: Q. Luan \\ E-mail: qifu.luan@caf.ac.cn
}

Genet. Mol. Res. 15 (3): gmr.15038982

Received July 20, 2016

Accepted August 1, 2016

Published August 29, 2016

DOI http://dx.doi.org/10.4238/gmr.15038982

Copyright $(C 2016$ The Authors. This is an open-access article distributed under the terms of the Creative Commons Attribution ShareAlike (CC BY-SA) 4.0 License.

\begin{abstract}
This is the first comprehensive study of the genetic analysis of the majority of oleoresin components of slash pine (Pinus elliottii). Pine oleoresin, the resin secreted from the pine tree, is a raw material widely used in industrial products. The objective of this study was to explore the genetic variation and correlation between the major oleoresin components of 50 open pollinated families of slash pine. The individual narrow-sense heritability of the 23 oleoresin components and genetic correlations between them were estimated using the residual maximum likelihood in the flexible mixed modeling program, ASReml-R. A high heritability of 0.424 was observed for $\beta$-pinene. Moderate levels of heritability were estimated for $\beta$-phellandrene, methyl abietate, estragole, 15-hydroxy-dehydroabietic acid, and isopimaric acid methyl ester at 0.303, 0.294, 0.27, 0.258, and 0.2, respectively. The heritabilities for pimaric acid methyl ester, abieta-8, 13-diene-18-oic acid methyl ester, sandaracopimaric acid, methyl ester, and camphene were relatively low and ranged from 0.11 to 0.17 . Many
\end{abstract}

Genetics and Molecular Research 15 (3): gmr.15038982 
negative genetic correlations were observed as unfavorable while the corresponding phenotypic correlations presented no significant relationships or positive phenotypic correlations. However, the heritabilities and genetic correlations showed that single or multiple component selections and improvement, directly or indirectly, were effective. We postulate that genetic parameters estimated in this study will work as a reference in breeding programs of oleoresin components, especially in slash pine.

Key words: Terpenoid; Oleoresin composition; Heritability; Genetic correlation; Genetic gain

\section{INTRODUCTION}

Slash pine, Pinus elliottii Engelm, having its origins in the southeastern United States is one of the most important species of the Southern yellow pine (Gholz et al., 1985). Because of its remarkable characteristics, which include rapid growth, wide adaptability, and high resin content, slash pine was introduced into China in the late 1940s and began to be planted in southern China on a large scale in the late 1970s (Wen et al., 2004). At present, more than 2 million hectares of slash pine is being grown in the southern provinces of China, making it one of the major timber and resin-tapping tree species in the country. Pine tree tapping for oleoresin is a significant activity in the process of social and economic development, especially in the developing countries (Cunningham, 2012). Therefore, it is tremendous ecological and economic importance in China.

Pine oleoresin, the resin secreted from the pine tree consists mainly of rosin: includes diterpenes, and turpentine: mono and sesquiterpenes (Trapp and Croteau, 2001). It is a raw material widely used in industrial products (FAO, 1995; Rodrigues-Corrêa et al., 2013). Oleoresin, a large-scale renewable resource, is favorably positioned as competition to chemical petroleum products as a viable alternative for sustainable development and environment protection in the current competitive global landscape (Lieutier et al., 2004). This characteristic has prompted immense scientific research on the resin generating mechanism (Wu and $\mathrm{Hu}, 1997)$, resistance function (Trapp and Croteau, 2001; Wainhouse et al., 2009), tapping techniques (Cunningham, 2012), and influence factors on yield improvement (Rodrigues et al., 2008; Rodríguez-García et al., 2015). Certain aspects of the oleoresin components have been also studied.

Rodrigues-Corrêa et al. (2013) reviewed the application of the components of oleoresin in different industries, including the pharmaceutical industry: camphene, isopimaric acid, isolongifolene; the cosmetics industry: carveol, $\alpha$-terpineol, $\beta$-caryopphyllene; insecticides: $\alpha$ - and $\beta$-pinene, farnesene; the food industry: bisabolene, germacrene, limonene; the chemical industry; carveol, farnesene, longifolene; and other such industries. Several studies have pointed out the variations in the composition of the resin between different tree species (Pureswaran et al., 2004), tapping periods (Mita et al., 2002), provenances (Arrabal et al., 2005), individuals (Latta et al., 2000), and the parts of tree (Vaičiulyte and Ložiené, 2013).

Furthermore, these components are most likely also influenced by genetic and environmental factors (Latta et al., 2003). The genetic variation and correlations between the major components of slash pine oleoresin help determine the selection of genetic resources of superior, high quality resin and emerges as the fundamental basis for the selective breeding of

Genetics and Molecular Research 15 (3): gmr.15038982 
the principal components. Previous researches on genetic analysis of the resin compositions focused on only one or a few components (Hanover, 1966; Squillace, 1971; Squillace et al., 1980; Yazdani et al., 1982; Pohjola et al., 1989; Gallis, 2005). According to data available, we are of the opinion that, at least for $P$. elliottii, this is the first comprehensive study on the genetic analysis of the majority of resin components. This study envisages a detailed study of the genetic parameter estimates for oleoresin compositions of slash pine with two main objectives: i) to investigate the inheritance of each oleoresin component, and ii) to estimate the genetic and phenotypic correlations between the 23 primary oleoresin components.

\section{MATERIAL AND METHODS}

\section{Experimental material}

The study was conducted in the Changle State Forest Farm located $30^{\circ} 27^{\prime} \mathrm{N}$ and $119^{\circ} 48^{\prime} \mathrm{E}$, in the northern Zhejiang province of southeast China. The experiment was conducted on the family test plantation of the Research Institute of Subtropical Forestry, Chinese Academy of Forestry established in the spring of 1994. It consisted of 50 open pollinated families collected from Taishan and Hangzhou located in the Guangdong and Zhejiang province, respectively. The experiment was conducted by a random complete block design of 6 replications and 6 trees per plot with the initial spacing of $2 \times 3 \mathrm{~m}$. The climate was subtropical monsoon climate, with a mean temperature of $16.1^{\circ} \mathrm{C}$ and an annual precipitation of $1399 \mathrm{~mm}$.

The sampling for oleoresin was carried out in August under conditions of high temperature and humidity for a span of three years, from 2012 to 2014. The average tree in each plot was taken as the sample tree. To obtain the oleoresin sample, a hole was drilled in the trunk at the diameter at breast-height on the side facing sunlight to ensure exclusion of the phloem. The sample was then collected (Figure 1) from the tree xylem in a sealed container. The collection tube was installed at $8 \mathrm{a} . \mathrm{m}$. and taken down approximately $24 \mathrm{~h}$ later. This process sequestered the oleoresin sample from the outside hermitically to protect it from contamination and oxidation and to keep it from being crystalized.

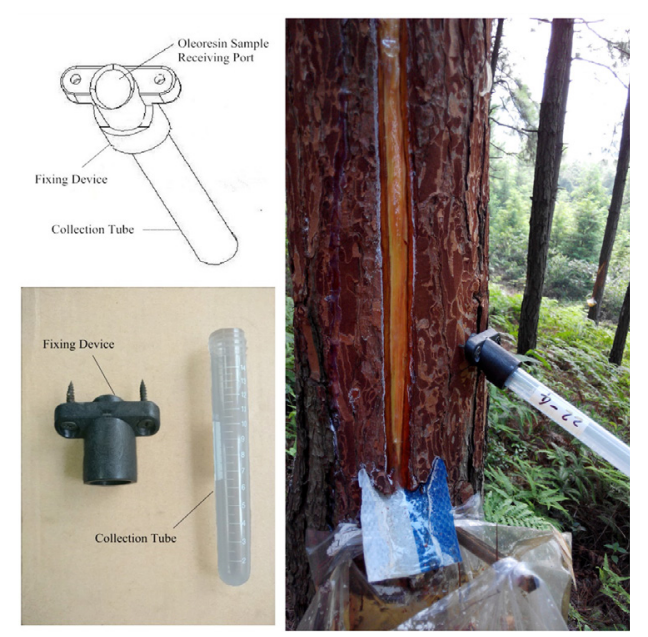

Figure 1. Resin collection device. 


\section{Resin composition determination}

The Gas Chromatography-Mass Spectrometry (GC-MS) method was carried out using an HP6890GC/5975B gas chromatograph and the mass spectrometry for qualitative and quantitative analysis of oleoresin composition with the chromatographic condition as follows (Song et al., 1988; Papajannopoulos et al., 2001); GC: $0.05 \mathrm{~g}$ of oleoresin was dissolved in 0.5 $\mathrm{ml}$ of ethyl alcohol containing $50 \mu \mathrm{L}$ tetramethylammonium hydroxide and analyzed by using a $30 \times 0.25 \times 0.25 \mathrm{~mm}$ i.d. HP-5MS silica capillary column. The initial column temperature was $60^{\circ} \mathrm{C}$ for $2 \mathrm{~min}$, increased to $80^{\circ} \mathrm{C}$ for $5 \mathrm{~min}$, and reaching a maximum of $280^{\circ} \mathrm{C}$ at a rate of $2^{\circ} \mathrm{C} \mathrm{min}{ }^{-1}$ for $5 \mathrm{~min}$. Injector temperature was $260^{\circ} \mathrm{C}$. The injection volume was $1 \mu \mathrm{L}$ with a $1 / 50$ split ratio. The carrier gas was Nitrogen. EI-MS: the electron energy was $70 \mathrm{eV}$. The connection parts and ion source temperatures were $250^{\circ}$ and $230^{\circ} \mathrm{C}$, respectively. The mass scan range was 30 to 600 amu along with solvent delay for $3 \mathrm{~min}$.

Oleoresin compositions were identified by matching experimental fragmentation patterns in mass spectra with NIST08 database through the data processing system of Agilent Chem Station and then comparing with the relevant literature (Song et al., 1993; Adams, 2001). The relative content of each component determined by peak area normalization is expressed as a percentage of the total amount of components. In this study, 7 monoterpenes and 16 diterpenes were detected and identified as shown in Table 1.

\section{Table 1.23 Oleoresin components of Pinus elliottii determined by GC-MS.}

\begin{tabular}{l|c|l|c|l|c}
\hline Diterpenes & Abbreviation & Diterpenes & Abbreviation & Monoterpenes & Abbreviation \\
\hline Methyl abietate & MEA & Methyl levopimarate & MEL & $\beta$-Pinene & BPI \\
\hline 15-Hydroxy-dehydroabietic acid & HYA & 8,15-Pimarene & PIE & $\beta$-Phellandrene & PHE \\
\hline Isopimaricacid methyl ester & IME & Methyl palustrate & MEP & Estragole & EST \\
\hline Pimaricacid methyl Ester & PME & Hydrogenated methyl pimaricate & HYM & Camphene & CAM \\
\hline Abieta-8,13-diene -18-oic acid methyl Ester & ABI & Isopimaral & ISO & $\alpha$-Pinene & API \\
\hline Sandaracopimaric acid, methyl ester & SAN & Pimaral & PIL & $\beta$-Myrcene & MYR \\
\hline$\beta$-Pimaric acid & PIA & Methyl dehydroabietate & MED & 1-Naphthoic acid & NAA \\
\hline Abieta-8,15-diene -18-oic acid methyl Ester & AME & Methyl-neoabietate & MEN & & \\
\hline
\end{tabular}

\section{Statistical analysis}

Data preprocessed by the arcsine-square-root transformation (Gulzar and Khan, 2001) were analyzed using Residual Maximum Likelihood (REML) in the flexible mixed modeling program ASReml-R (Butler et al., 2009) which has been developed as an R package. The linear mixed model used to estimate variance components and genetic parameters was:

$Y_{i j k}=\mu+R_{i}+F_{j}+Y_{k}+R \times F_{i j}+F \times Y_{j k}+R \times Y_{i k}+R \times F \times Y_{i j k}+e \quad$ (Equation 1)

where $Y_{i j k}$ is an observation of each oleoresin component of the $i j k$ th tree, $R_{i}$ represents the fixed effect of the $i$ th replicate, $F_{j}$ and $Y_{k}$ represent the random effects of the $j$ th family and $k$ th year of sampling and $e$ is the random vector of residual terms.

Estimates of heritability and genetic correlations for oleoresin components were obtained using the variance components from the univariate and bivariate analyses. Standard errors were calculated using the Taylor series expansion method (Namkoong, 1979) in

Genetics and Molecular Research 15 (3): gmr.15038982 
ASReml-R (Butler et al., 2009; Gilmour et al., 2014). The individual narrow-sense heritability for each oleoresin component was estimated as follows:

$$
\mathrm{h}^{2}=\frac{4 \sigma_{\mathrm{F}}^{2}}{\sigma_{\mathrm{F}}^{2}+\sigma_{\mathrm{RF}}^{2}+\sigma_{\mathrm{FY}}^{2}+\sigma_{\mathrm{Y}}^{2}+\sigma_{\mathrm{e}}^{2}}
$$

Here, $\sigma_{\mathrm{F}}^{2}, \sigma_{\mathrm{RF}}^{2}, \sigma_{\mathrm{FY}}^{2}, \sigma_{\mathrm{Y}}^{2}$ and $\sigma_{\mathrm{e}}^{2}$ represented the estimated variance components for families, the replicate $\mathrm{x}$ family interaction, the family $\mathrm{x}$ year interaction, years and the residual, respectively.

The genetic correlation $r_{\mathrm{g}}$ between two components was estimated within the ASReml-R software as:

$$
r_{g}=\frac{\sigma_{\mathrm{AxAy}}}{\sqrt{\left(\sigma_{\mathrm{Ax}}^{2} \sigma_{\mathrm{Ay}}^{2}\right)}}
$$

where $\sigma_{\text {AxAy }}$ represents the additive covariance component between resin composition $\mathrm{x}$ and $\mathrm{y}, \sigma_{\mathrm{Ax}}^{2}$ and $\sigma_{\mathrm{Ay}}^{2}$ represent the additive variance components for resin composition $\mathrm{x}$ and $\mathrm{y}$, respectively.

$$
r_{p}=\frac{\sigma_{A x A y}+\sigma_{R}^{2}}{\sqrt{\left(\sigma_{A x}^{2}+\sigma_{R x}^{2}\right)\left(\sigma_{A y}^{2}+\sigma_{R y}^{2}\right)}}
$$

where $\sigma_{R}^{2}$ represents the residual covariance components between resin composition $\mathrm{x}$ and $\mathrm{y}, \sigma_{R x}^{2}$ and $\sigma_{R y}^{2}$ represent the residual variance components for resin composition $\mathrm{x}$ and $\mathrm{y}$, respectively.

The prediction of genetic gain $\mathrm{G}_{\mathrm{a}}$ using formula (Namkoong, 1996) as follows:

$$
\mathrm{G}_{\mathrm{a}}=\frac{\mathrm{S}}{\overline{\mathrm{X}}} \cdot \mathrm{h}_{\mathrm{a}}^{2}
$$

where $\mathrm{S}, \overline{\mathrm{X}}$ and $\mathrm{h}_{\mathrm{a}}^{2}$ represent the selection differential, average content of each component, and the heritability for oleoresin component a. In this study, we take $10 \%$ as the selection rate to calculate the selection differential S.

The efficiency of selection for one trait over another trait (White et al., 2007) was estimated as:

$$
E=r_{g} \times \frac{h_{x}}{h_{y}}
$$

where $h_{x}$ and $h_{y}$ are the square roots of narrow-sense heritability of component $\mathrm{x}$ and $\mathrm{y}$, respectively.

Visualization of the genetic correlation matrix was done using the R package, corrplot (Wei, 2013). It is noteworthy that in all analyses, the interaction between replicate, family and year effects was dropped from the model when corresponding (co)variances were not significantly different from zero (Butler et al., 2009; Gilmour et al., 2014).

Genetics and Molecular Research 15 (3): gmr.15038982 


\section{RESULTS AND DISCUSSION}

\section{Descriptive statistics}

Means, standard deviation and coefficient of variation of each oleoresin component are shown in Table 2. In all, 23 components were detected in this study including 7 monoterpenes and 16 diterpenes with a percent content of 9.89 and $85.66 \%$ respectively. However, the mono-, di- and sesquiterpenes were not identified accounting for only about $4.45 \%$ of the total.

\begin{tabular}{|c|c|c|c|}
\hline Components & Mean (\%) & SD & CV (\%) \\
\hline Monoterpenes & 9.89 & & \\
\hline BPI & 2.65 & 1.32 & 49.93 \\
\hline PHE & 0.46 & 0.37 & 80.55 \\
\hline EST & 0.10 & 0.10 & 93.68 \\
\hline CAM & 0.08 & 0.03 & 29.72 \\
\hline API & 5.09 & 1.40 & 27.49 \\
\hline MYR & 0.08 & 0.03 & 33.76 \\
\hline NAA & 1.43 & 2.17 & 151.67 \\
\hline Diterpenes & 85.66 & & \\
\hline MEA & 9.01 & 1.67 & 18.52 \\
\hline HYA & 0.24 & 0.15 & 65.27 \\
\hline IME & 15.01 & 2.14 & 14.26 \\
\hline PME & 3.93 & 1.48 & 37.58 \\
\hline $\mathrm{ABI}$ & 17.03 & 2.20 & 12.91 \\
\hline SAN & 0.78 & 0.82 & 104.85 \\
\hline PIA & 0.13 & 0.08 & 58.87 \\
\hline AME & 0.41 & 0.28 & 67.65 \\
\hline MEL & 29.93 & 4.62 & 15.44 \\
\hline PIE & 1.92 & 1.93 & 100.44 \\
\hline MEP & 0.37 & 0.57 & 155.59 \\
\hline HYM & 0.74 & 0.71 & 95.38 \\
\hline ISO & 2.18 & 1.48 & 67.80 \\
\hline PIL & 0.71 & 0.41 & 57.45 \\
\hline MED & 2.76 & 2.06 & 74.83 \\
\hline MEN & 0.51 & 0.66 & 130.92 \\
\hline
\end{tabular}

$\mathrm{SD}$, standard deviation; $\mathrm{CV}$, coefficient of variation.

The main components of monoterpenes were API, BPI and NAA, which accounted for $92.72 \%$ of the total. Pimaric- (IME, PME, SAN, PIA, PIE, and HYM) and abietic-type resin acids (MEA, HYA, ABI, AME, MEL, MED, and MEN) were the main components of the diterpenes and comprised 26.28 and $69.85 \%$ of each, respectively.

Furthermore, the content of MEL (diterpene) was the highest; accounting for $29.93 \%$ in all of the oleoresin components, and the content of MYR, a monoterpene was the lowest at $0.08 \%$. Coefficients of variation (CV) of MEP, NAA, MEN, SAN, PIE, HYM, and EST were substantially higher, showing a large variation in their relative amounts in these components of slash pine trees. This is indicative of the fact that one or several components among them can be effectively selected.

\section{Heritabilities}

Most of the research conducted on the genetic analysis of the oleoresin compositions,

Genetics and Molecular Research 15 (3): gmr.15038982 
has been focused only on one or a few components limited by the concurrent conditions and resources (Hanover, 1966; Squillace, 1971; Squillace et al., 1980; Yazdani et al., 1982; Pohjola et al., 1989; Gallis, 2005).

In our findings, individual narrow-sense heritability for each oleoresin monoterpene component was overall low, from 0.002 to 0.424 (Table 3 ) compared to reports from previous studies that focused on broad-sense heritability and showed results ranging from 0.19 to 0.89 (Squillace, 1971; Meier and GoggAns, 1978). As shown in Table 3, BPI ( $\beta$-pinene) revealed a high heritability of $0.424 \pm 0.19$. Estimated heritabilities for PHE ( $\beta$-phellandrene), MEA (methyl abietate), EST (estragole), HYA (15-hydroxydehydroabietic acid) and IME (isopimaricacid methyl ester) were $0.303,0.294,0.27,0.258$ and 0.2 , respectively, which were at a moderate level. The heritabilities for PME, ABI, SAN and CAM were relatively low, from 0.11 to 0.17 . Estimates of individual narrow-sense heritabilities of the other 13 oleoresin components were almost negligible ranging from 0.005 to 0.068 .

Table 3. Estimates of individual narrow-sense heritability for each oleoresin component.

\begin{tabular}{l|c|c|c}
\hline Components & $\mathrm{h}^{2}$ & $\mathrm{SE}$ & $\mathrm{G}$ (\%) \\
\hline Monoterpenes & & & 20.18 \\
\hline BPI & 0.424 & 0.19 & 25.17 \\
\hline PHE & 0.303 & 0.18 & 28.29 \\
\hline EST & 0.27 & 0.159 & 1.38 \\
\hline CAM & 0.11 & 0.069 & 0.86 \\
\hline API & 0.055 & 0.1 & 0.40 \\
\hline MYR & 0.03 & 0.01 & 4.65 \\
\hline NAA & 0.002 & & 16.47 \\
\hline Diterpenes & & 0.168 & 2.42 \\
\hline MEA & 0.294 & 0.172 & 4.52 \\
\hline HYA & 0.258 & 0.141 & 18.00 \\
\hline IME & 0.2 & 0.124 & 16.23 \\
\hline PME & 0.17 & 0.145 & 3.90 \\
\hline ABI & 0.154 & 0.136 & 3.47 \\
\hline SAN & 0.144 & 0.076 & 0.66 \\
\hline PIA & 0.068 & 0.114 & 2.18 \\
\hline AME & 0.05 & 0.087 & 2.86 \\
\hline MEL & 0.047 & 0.027 & 1.78 \\
\hline PIE & 0.02 & 0.065 & 1.21 \\
\hline MEP & 0.02 & 0.081 & 1.04 \\
\hline HYM & 0.02 & 0.026 & 0.34 \\
\hline ISO & 0.02 & 0.076 & 0.59 \\
\hline PIL & 0.02 & 0.02 & \\
\hline MED & 0.005 & 0.01 & \\
\hline MEN & 0.004 & & \\
\hline SE, & & & \\
\hline
\end{tabular}

$\mathrm{SE}$, standard error; $\mathrm{G}_{\mathrm{a}}$, genetic gain.

This shows that it is possible to make effective selections to obtain high yield and quality resin, with excellent pedigree or individuals, through the process of selective breeding in accordance with specific objectives for these 10 components.

Taking $10 \%$ as the selection rate to select the plus trees, the prediction of genetic gain for each component is shown in Table 3. High genetic gains were observed for BPI (20.18\%), PHE (25.17\%) and EST (28.29\%). BPI and PHE also possess insect-resistant characteristics, 
as they are able to repel or poison bark beetles (Hodges et al., 1979; Raffa et al., 1998). Therefore, the selection of genetically superior BPI and PHE would be beneficial to ward off insect attacks. Genetic gains larger than $10 \%$ were observed for HYA, ABI and SAN, which could also prove useful for selection. The genetic gains for other components were however negligible $(<5 \%)$.

\section{Genetic and phenotypic correlations}

Figure 2 and Figure 3 show genetic and phenotypic correlations between the 23 oleoresin components, respectively. The information in the circle diagram (bottom left) and the number (top right) of the figure is the same as the correlation coefficient between each of the two components. The blue area represents positive correlation while the red area shows negative correlation. The darker the color, and larger the circle area, the greater is the value of the correlation.

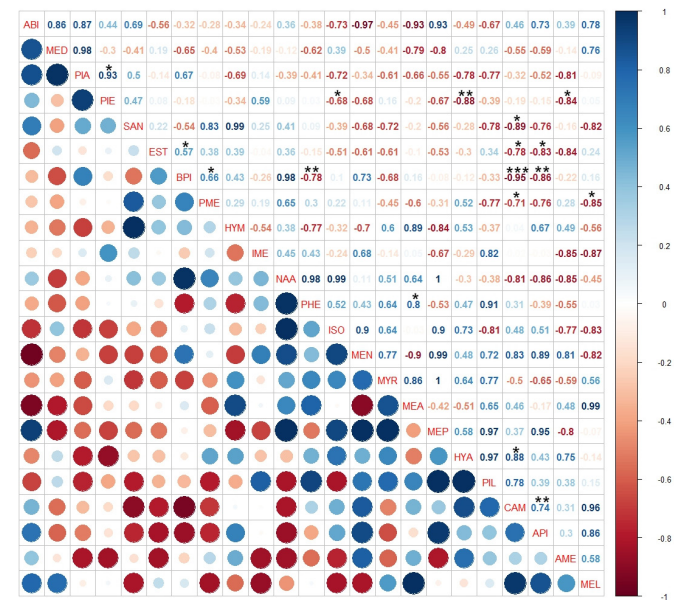

Figure 2. Estimates of genetic correlations between 23 oleoresin compositions. Blue represents positive correlation; Red represents negative correlation; *, **, and *** represent $\mathrm{P}<0.05, \mathrm{P}<0.01$ and $\mathrm{P}<0.001$, respectively.

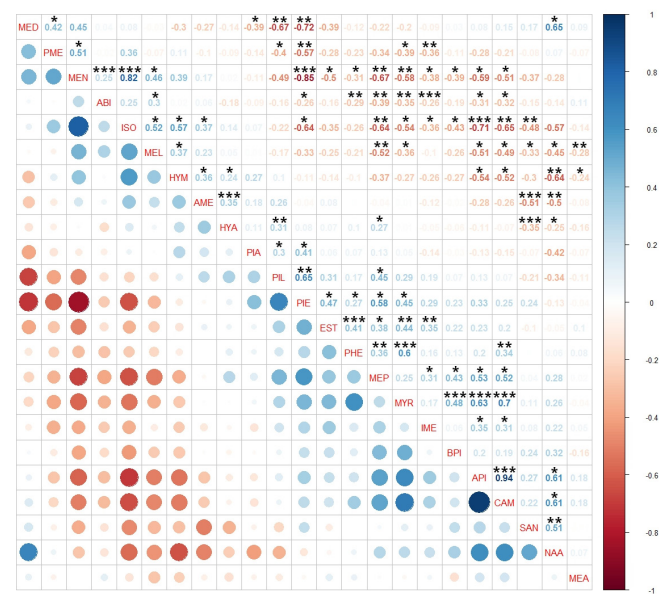

Figure 3. Estimates of phenotypic correlations between 23 oleoresin compositions.

Genetics and Molecular Research 15 (3): gmr.15038982 
For monoterpenes, the genetic correlations between API and BPI with EST were highly negatively significant ( $-0.86 \pm 0.36$ and $-0.83 \pm 0.53$, respectively). Nonetheless, API appeared to be independently inherited from BPI and EST. The second major monoterpene component, BPI, showed significantly moderate positive genetic correlations with EST and PME, and with PHE and CAM, it showed significant negative correlations. It is worth mentioning that the negative genetic correlation between BPI and CAM $(-0.95 \pm 0.26)$ was highly significant $(\mathrm{P}<$ 0.001). API and CAM show strong antifeedant and oviposition deterrence effect on Dendrolimus spp (Yan et al., 2007). The negative genetic correlations among such components appear to present a constraint on the defense against different insects (Latta et al., 2003). Thus, different components, BPI or CAM, can be selected in accordance to different practical requirements in conventional breeding. The other important component CAM, displayed highly negative genetic correlations with EST, PME and SAN, and highly positive and significant genetic correlations with API (also highly positive phenotypic correlation) and HYA.

For pimaric-type resin acids, PIE was significant and highly positive $(0.93 \pm 0.42)$ and also moderately phenotypically $(0.41 \pm 0.20)$ correlated with PIA. However, it showed negative genetic correlations with HYA, ISO and AME.

In the abietic-type resin acids, the genetic correlation between MEL (the component with the biggest content of $29.93 \%)$ and PME was highly negatively significant $(-0.85 \pm 0.55)$. MEA had a highly significant negative genetic correlation with PHE $(0.8 \pm 0.37)$.

The pimaric-type resin acids are proved to have positive antibacterial, antimicrobial, insecticidal properties (Smith et al., 2005; Rubio et al., 2005). They have a significant potential in medicine, biological pesticides and other fields. Pimaric-type resin acids can also be used as a comprehensive trait for genetic improvement in the selection of slash pine.

In breeding programs, negative genetic correlations are unfavorable for selection of multiple components for improvement at the same time. However, it is interesting to note that contrary to genetic correlations, some components presented no significant or positive correlations on phenotype. For example, BPI had low positive correlations with API ( $0.20 \pm$ $0.30)$ and CAM $(0.19 \pm 0.29)$ with no significance. This showed that components with negative genetic correlations could be improved simultaneously under specific environmental conditions.

Thus, genetic correlations of these components can provide a reference for the selection of multiple components by predicting how selection for one or several traits would affect the correlated traits in the next generation. Needless to say, we could improve the components with positive correlation and simultaneously select the components taking into consideration, the breeding improvement target with negative correlation. What is more, for components with low content and heritabilites which are difficult to improve directly, an approach of indirect prediction and selection could be applied by using the highly correlated components with high content and heritabilities. For example, high genetic correlation $\left(r_{g}=0.74 \pm 0.26, \mathrm{P}<0.01\right)$ between CAM $\left(h^{2}=0.11\right)$ and API $\left(h^{2}=0.055\right)$ renders indirect selection for API with $99.78 \%$ selection efficiency when selection is based on CAM.

\section{CONCLUSIONS}

We estimated the genetic correlations for oleoresin components of slash pine, Pinus elliottii for 50 open pollinated families grown on the Changle State Forest Farm $\left(30^{\circ} 27^{\prime} \mathrm{N}\right.$, $119^{\circ} 48^{\prime} \mathrm{E}$ ) in northern Zhejiang province, southeast China. Our findings were as follows:

The content of monoterpenes and diterpenes is about 9.89 and $85.66 \%$ respectively

Genetics and Molecular Research 15 (3): gmr.15038982 
(Table 2). For monoterpenes, API, BPI and NAA are the main components which account for 92.72\%. Pimaric- (IME, PME, SAN, PIA, PIE, HYM) and abietic-type resin acids (MEA, HYA, ABI, AME, MEL, MED, MEN) are the main components of diterpenes that comprised 26.28 and $69.85 \%$.

For individual narrow-sense heritabilities, BPI, PHE, MEA, EST, HYA, and IME were at a moderately high level ranging from 0.2 to 0.424 . The heritabilities for PME, ABI, SAN, and CAM were relatively lower, from 0.11 to 0.17 . The selection of the best $10 \%$ for BPI, PHE, EST, HYA, ABI, and SAN would result in direct genetic gains.

As for genetic and phenotypic correlations, the genetic correlations between API and BPI, EST were highly significant negatively. BPI, showed significant moderate positive genetic correlations with EST and PME. And with PHE and CAM, it showed significant negative correlations. CAM had highly negative genetic correlations with EST, PME and SAN, and highly significant positive genetic correlations with API (also with the highly positive phenotypic correlation) and HYA. PIE showed significant positive correlation with PIA, and negative genetic correlations with HYA, ISO and AME. The genetic correlation between MEL and PME was highly significant negatively and MEA was negative with PHE in genetic gain.

Therefore, despite genetic correlations, some components presented no significant phenotypic correlations or positive phenotypic correlations. It can therefore be inferred that components with negative genetic correlations have the potential to also be improved simultaneously under the influence of the specific environmental conditions.

\section{Conflicts of interest}

The authors declare no conflict of interest.

\section{ACKNOWLEDGMENTS}

We thank Yuanzhen Lin of the South China Agricultural University for assistance in data processing using ASReml-R and in the visualization of the genetic correlation matrix using R package corrplot. Research supported by the National Science \& Technology Pillar Program of China (\#2012BAD01B0203, http://kjzc.jhgl.org/) and the National Natural Science Foundation of China (\#31570668).

\section{REFERENCES}

Adams RP (2001). Identification of essential oil components by gas chromatogratography/quadropole mass spectroscopy. 4th edn. Allured Publishing Corporation, Illinois.

Arrabal C, Cortijo M, de Simón BF, Vallejo MCG, et al. (2005). Differentiation among five Spanish Pinus pinaster provenances based on its oleoresin terpenic composition. Biochem. Syst. Ecol. 33: 1007-1016. http://dx.doi. org/10.1016/j.bse.2005.03.003

Butler DG, Cullis BR, Gilmour AR and Gogel BJ (2009). ASReml-R reference manual. Queensland Department of Primary Industries. Available at [http://www.vsni.co.uk/zh/resources/documentation/].

Cunningham A (2012). Pine resin tapping techniques. In: Pine resin: biology, chemistry and applications (Fett-Neto AG and Rodrigues-Corrêa KCS, eds.). Research Signpost, Kerala, India.

FAO (1995). Flavors and fragrances of plant origin. Non-wood forest products 1. Natural Resources Institute, FAO, Rome. Gallis AT (2005). Study of the genetic control of four volatile monoterpenes in Pinus brutia x Pinus halepensis hybrids. Implications for protection and management of forest ecosystems in Greece. In the 9th International Conference on Environmental Science and Technology, G-NEST and University of Aegean.

Genetics and Molecular Research 15 (3): gmr.15038982 
Gholz HL, Fisher RF and Prichett WL (1985). Nutrient dynamics in slash pine plantation ecosystems. Ecology 66: 647659. http://dx.doi.org/10.2307/1940526

Gilmour AR, Gogel BJ, Cullis BR, Welham SJ, et al. (2014). ASReml User Guide Release 4.1 Functional Specification. VSN International Ltd, Hemel Hempstead, HP1 1ES, UK. Available at [http://www.vsni.co.uk/zh/resources/ documentation/].

Gulzar S and Khan MA (2001). Seed germination of halophytic grass Aeluropus lagopoides. Ann. Bot. 87: 319-324. http:// dx.doi.org/10.1006/anbo.2000.1336

Hanover JW (1966). Inheritance of 3-carene concentration in Pinus monticola. For. Sci. 12: 447-450.

Hodges JD, Elam WW, Watson WF and Nebeker TE (1979). Oleoresin characteristics and susceptibility of four southern pines to southern pine beetle (Coleoptera: Scolytidae) attacks. Can. Entomol. 111: 889-896. http://dx.doi.org/10.4039/ Ent111889-8

Latta RG, Linhart YB, Lundquist L and Snyder MA (2000). Patterns of monoterpene variation within individual trees in ponderosa pine. J. Chem. Ecol. 26: 1341-1357. http://dx.doi.org/10.1023/A:1005471322069

Latta RG, Linhart YB, Snyder MA and Lundquist L (2003). Patters of variation and correlation in the monoterpene composition of xylem oleoresin within populations of ponderosa pine. Biochem. Syst. Ecol. 31: 451-465. http:// dx.doi.org/10.1016/S0305-1978(02)00176-X

Lieutier F, Day KR, Battwasti A, Gregoire JC, et al. (2004). Bark and wood boring insects in living trees in Europe. 1st edn. Kluwer Academic Publishers, Dordrecht.

Meier R J and GoggAns JF (1978). Heritabilities and correlations of the cortical monoterpenes of Virginia pine (Pinus virginiana Mill.). Silvae Genet. 27: 79-84.

Mita E, Tsitsimpikou C, Tsiveleka L, Petrakis PV, et al. (2002). Seasonal variation of oleoresin terpenoids from Pinus halepensis and Pinus pinea and host selection of the scale insect Marchalina hellenica (Homoptera, Coccoidea, Margarodidae, Coelostonidiinae). Holzforschung 56: 572-578. http://dx.doi.org/10.1515/HF.2002.087

Namkoong G (1979). Introduction to quantitative genetics in forestry. USDA For. Serv. Tech. Bull. 1588: 342.

Namkoong G (1996). Introduction to quantitative genetics in forestry. 4th edn. Castle House Publications, London.

Papajannopoulos AD, Song ZQ, Liang ZQ and Spanos JA (2001). GC-MS analysis of oleoresin of three Greek pine species. Eur. J. Wood Wood Prod 59: 443-446. http://dx.doi.org/10.1007/s00107-001-0249-x

Pohjola J, Hiltunen R and Schantz MV (1989). Variation and inheritance of terpenes in Scots pine. Flavour Fragrance J. 4: 121-124. http://dx.doi.org/10.1002/ffj.2730040308

Pureswaran DS, Gries R and Borden JH (2004). Quantitative variation in monoterpenes in four species of conifers. Biochem. Syst. Ecol. 32: 1109-1136. http://dx.doi.org/10.1016/j.bse.2004.04.006

Raffa KF, Krause SC and Reich PB (1998). Long-term effects of defoliation on red pine suitability to insects feeding on diverse plant tissues. Ecology 79: 2352-2364. http://dx.doi.org/10.1890/0012-9658(1998)079[2352:LTEODO]2.0. $\underline{\mathrm{CO} ; 2}$

Rodrigues KCS, Azevedo PCN, Sobreiro LE, Pelissari P, et al. (2008). Oleoresin yield of Pinus elliottii plantations in a subtropical climate: effect of tree diameter, wound shape and concentration of active adjuvants in resin stimulating paste. Ind. Crops Prod. 27: 322-327. http://dx.doi.org/10.1016/j.indcrop.2007.11.010

Rodrigues-Corrêa KCS, Lima JC and Fett-Neto AG (2013). Oleoresins from pine: Production and industrial uses. In: Natural Products. 1st edn. Springer Berlin Heidelberg, Berlin.

Rodríguez-García A, Martín JA, López R, Mutke S, et al. (2015). Influence of climate variables on resin yield and secretory structures in tapped Pinus pinaster Ait. in central Spain. Agric. For. Meteorol. 202: 83-93. http://dx.doi. org/10.1016/j.agrformet.2014.11.023

Rubio J, Calderón JS, Flores A, Castroa C, et al. (2005). Trypanocidal activity of oleoresin and terpenoids isolated from Pinus oocarpa. Z. Naturforsch., C, J. Biosci. 60: 711-716. http://dx.doi.org/10.1515/znc-2005-9-1009

Smith E, Williamson E, Zloh M and Gibbons S (2005). Isopimaric acid from Pinus nigra shows activity against multidrugresistant and EMRSA strains of Staphylococcus aureus. Phytother. Res. 19: 538-542. http://dx.doi.org/10.1002/ ptr.1711

Song ZQ, Chen LC and Perry JP (1988). Characterization of mono-, sesqui- and diterpenes in some Mexican and Guatemalan pine oleoresin - a simple GC method. Chemistry and Industry of Forest Products 8: 10-18.

Song Z Q, Liu X, Liang ZQ and Wang WL (1993). Chemical characteristics of oleoresins of some exotic pines. Chemistry and Industry of Forest Products 13: 277-287.

Squillace AE (1971). Inheritance of monoterpene composition in cortical oleoresin of slash pine. For. Sci. 17: 381-387.

Squillace AE, Wells OO and Rockwood DL (1980). Inheritance of monoterpene composition in cortical oleoresin of loblolly pine. Silvae Genet. 29: 141-152.

Trapp S and Croteau R (2001). Defensive resin biosynthesis in conifers. Annu. Rev. Plant Physiol. Plant Mol. Biol. 52: 689-724. http://dx.doi.org/10.1146/annurev.arplant.52.1.689

Genetics and Molecular Research 15 (3): gmr.15038982 
Vaičiulytė V and Ložienė K (2013). Variation of Chemical and Morphological Characters of Leaves and Unripe Cones in Juniperus Communis. Botanica Lithuanica 19: 37-47. http://dx.doi.org/10.2478/botlit-2013-0005

Wainhouse D, Staley JT, Jinks R and Morgan G (2009). Growth and defence in young pine and spruce and the expression of resistance to a stem-feeding weevil. Oecologia 158: 641-650. http://dx.doi.org/10.1007/s00442-008-1173-0

Wei T Y (2013). corrplot: visualization of a correlation matrix, Version 0.71. The Comprehensive R Archive Network, Vienna, Austria. Available at [http://cran.r-project.org/web/packages/corrplot/corrplot.pdf].

Wen X, Kuang Y, Shi M, Li H, et al. (2004). Biology of Hylobitelus xiaoi (Coleoptera: Curculionidae), a new pest of slash pine, Pinus elliottii. J. Econ. Entomol. 97: 1958-1964. http://dx.doi.org/10.1603/0022-0493-97.6.1958

White TL, Adams WT and Neale DB (2007). Forest genetics. CABI Publishing, CAB International, Wallingford.

$\mathrm{Wu} \mathrm{H}$ and $\mathrm{Hu} \mathrm{ZH}$ (1997). Comparative anatomy of resin ducts of the pinaceae. Trees 11: 135-143. http://dx.doi. org $/ 10.1007 / \mathrm{s} 004680050069$

Yan SC, Xu W, Yuan HE, Wang Q, et al. (2007). Effects of different elicitors on olfactory response and oviposition selection of Dendrolimus superans (Butler). Ying Yong Sheng Tai Xue Bao 18: 1583-1588.

Yazdani R, Rudin D A G, Aldén T, Lindgern D, et al. (1982). Inheritance pattern of five monoterpenes in Scots pine (Pinus sylvestris L.). Hereditas 97: 261-272. http://dx.doi.org/10.1111/j.1601-5223.1982.tb00770.x

Genetics and Molecular Research 15 (3): gmr.15038982 